\title{
GREENHOUSE IMPLEMENTATION ON FLOW SEPARATION IN DIFFUSERS
}

\author{
A.S. Abdelhameed and A. AbdElmotalip \\ Mechanical Power Department, Faculty of Engineering Port-Said, \\ Suez Canal University, Egypt
}

\begin{abstract}
An experimental investigation was carried out to study the greenhouse adaptation, as a method, to prevent separation at different values of Reynolds numbers in a sub-sonic two-dimensional flatwalled diffuser.

The greenhouse implementation is attained by using a cotton screen, as impedance, of specific porosity to slow down the hot air flow near the exit of the diffuser. The average velocity and fluctuation fields have been measured with a constant temperature hot-wire anemometer (CTA).However, in reversed flow zones pressures have been measured using 5-hole-probe.

The experimental measurements of velocity and pressure were made at six stations of the diffuser, for different Reynolds numbers and specific value of porosity. The experimental results showed that the greenhouse can be used to achieve separation delay, separation prevention, and pressure recovery coefficient improvement in particular, for increasing Reynolds number. However, using the greenhouse adaptation to prevent separation is not the only advantage but, the results show that the diffuser is capable of giving a good performance and having a decreased boundary layer thickness.

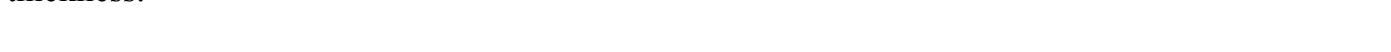

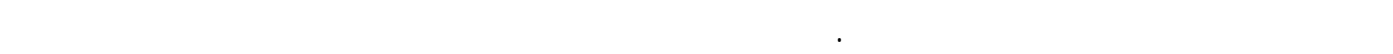

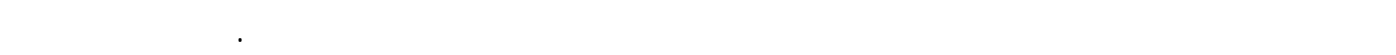

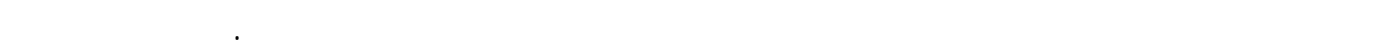

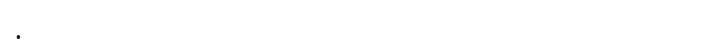

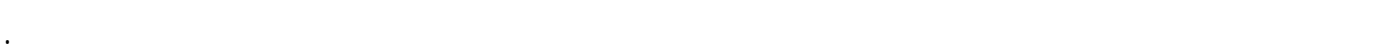

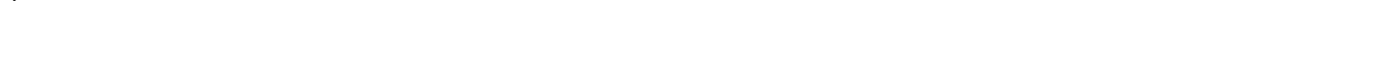

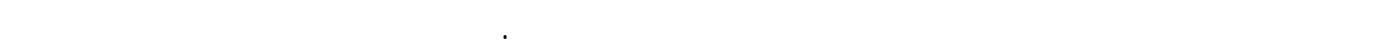

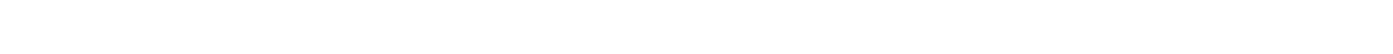

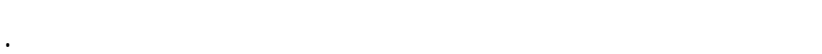

keywords: Greenhouse, adaptation, separation, impedance, porosity, pressure recovery coefficient, boundary layer thickness.

\section{INDRODUCTION}

In general, the field of flow-separation control is far richer than the conventional view, which usually considers only suction, injection, and vortex generators. For decades, researchers have proven that separation control, in most of its guises, will work. The task of researchers and designers now is to improve reliability, where necessary, and increase net gains through innovation. This richness of existing approaches for flow separation control is mirrored in the extensive literature partially available for lowspeed flows in the publications by Lachmann [1], Colin and Williams [2], Chang [3], Adkins [4], Gadel-Hak [5,6], Lin, Howard, Bushnell, and Selby [7], and Gad-el-Hak and Bushnell [8,9] and references therein as well as herein. In high speed-flows, excellent reviews for separation control in shockboundary-layer interactions are provided by Delery [10], Viswanath [11] and MacCormack [12]. Probably the most popular flow-separation control technique has been to add momentum to the near-wall region (MacMartin [13]) either actively (e.g., tangential blowing or wall jets) or passively (e.g., boundary layer tripping, turbulence enhancement, or vortex generators of various scales).

The recent advances in computational fluid dynamics are allowing the transformation of much of boundary layer control from an empirical art to a predictive science. Separation control is addressed for both nominally two-dimensional and three- dimensional flows, although the knowledge base concerning the latter is noticeably deficient. Typically, threedimensional separation occurs sooner but is less catastrophic than the quasi two-dimensional case (Driver [14]). For historical reasons, most of the separation control methods mentioned here was developed for aircraft wings. The results, however, pertain to fundamental properties of fluid flow and could readily be extended to a variety of systems such as diffusers, steam turbine blades, wind turbine 
rotors, pump impellers, and off-shore structure components.

In the present work, a new approach of adapting the greenhouse effect to prevent separation in flat-walled diffusers is presented. This adds a negative contribution to the curvature of the velocity profile at the wall and, hence, causes the separation point to move farther aft. In that case, the velocity gradient near the wall increases and the velocity profile becomes fuller and more stable. This method of separation control has been successfully applied through an experimental verification for different Reynolds numbers and specific value of porosity.

\section{NOMENCLATURE}

$\mathrm{A}_{1} \quad$ Cross-sectional area at inlet, $=\left(\mathrm{W}_{1} * \mathrm{~W}_{1}\right),\left(\mathrm{m}^{2}\right)$

$\mathrm{A}_{2}$ Cross-sectional area at exit, $=\left(\mathrm{W}_{2} * \mathrm{~W}_{2}\right),\left(\mathrm{m}^{2)}\right.$

$\mathrm{C}_{\mathrm{Pi}} \quad$ Ideal pressure recovery coefficient, $=1-(1 /$ $\left.\left(A_{r}\right)^{2}\right)$

$\mathrm{C}_{\mathrm{P}}$ Overall pressure recovery coefficient, = $\Delta \mathrm{P} / 0.5 \rho \mathrm{U}_{\mathrm{o}}^{2}$

$\mathrm{k} \quad$ Impedance of the screen

$\mathrm{N} \quad$ Diffuser axial length, (m)

$\mathrm{P}_{1} \quad$ Static pressure at inlet, $(\mathrm{Pa})$

$\mathrm{P}_{2} \quad$ Static pressure at exit, $(\mathrm{Pa})$

Re Reynolds number at inlet, $=\rho \mathrm{U}_{\mathrm{o}} \mathrm{W}_{1} / \mu$

$\mathrm{T} \quad$ Mean temperature at inlet diffuser, $\left({ }^{\circ} \mathrm{C}\right)$

$\mathrm{U}$ Mean velocity in the diffuser, $(\mathrm{m} / \mathrm{sec})$

$\mathrm{U}_{\mathrm{e}} \quad$ Mean velocity at station $6,(\mathrm{~m} / \mathrm{sec})$

$\mathrm{U}(\mathrm{x})$ Core velocity, $(\mathrm{m} / \mathrm{sec})$

$\mathrm{U}_{\mathrm{o}}$ Mean velocity in the inlet cross-section, $(\mathrm{m} / \mathrm{sec})$

$\mathrm{u} \quad$ Local mean velocity component, $(\mathrm{m} / \mathrm{sec})$

$\mathrm{U}^{*} \quad$ Dimensionless velocity, $=\mathrm{u} / \mathrm{U}$

$\mathrm{x} \quad$ Axial distance measured from diffuser inlet, (m)

y Normal distance to wall, (m)

$\mathrm{X}^{*} \quad$ Non-dimensional axial distance, $=\mathrm{x} / \mathrm{N}$

$\mathrm{Y}^{*} \quad$ Non-dimensional normal distance, $=\mathrm{y} / \mathrm{y}_{\mathrm{s}}$

$\mathrm{W}_{1} \quad$ Diffuser width at inlet, (m)

$\mathrm{W}_{2} \quad$ Diffuser width at exit, $(\mathrm{m})$

$\Delta \mathrm{P} \quad$ Diffuser recovery pressure, $=\left(\mathrm{P}_{2}-\mathrm{P}_{1}\right),(\mathrm{Pa})$

$\Delta \mathrm{P}_{\mathrm{e}} \quad$ Static pressure (gage) at Station $4,=\mathrm{k}$ $\left(0.5 \rho \mathrm{U}_{\mathrm{e}}^{2}\right),(\mathrm{Pa})$

$\mathrm{du} / \mathrm{dx}$ Velocity gradient in $\mathrm{x}$-direction, $(1 / \mathrm{sec})$

$\mathrm{dP} / \mathrm{dx}$ Pressure gradient in $\mathrm{x}$-direction, $\left(\mathrm{N} / \mathrm{m}^{3}\right)$

$\mathrm{du} /$ dy Velocity gradient in y-direction, $(1 / \mathrm{sec})$

$\mathrm{d}^{2} \mathrm{u} / \mathrm{dy}^{2}$ Second derivative of velocity in $\mathrm{y}$-direction, $(1 / \mathrm{m} . \mathrm{sec})$

$\varepsilon_{\mathrm{m}}$ Mean porosity of the cotton screen, $=$ $1 / \sqrt{1+\frac{\mathrm{k}}{0.52}}$

$\tau_{\mathrm{w}} \quad$ Shear stress at the wall, $=\mu .(\mathrm{du} / \mathrm{dy})_{\mathrm{y}=0.0 \text {, }}$ $\left(\mathrm{N} / \mathrm{m}^{2}\right)$

$\rho \quad$ Air density, $\left(\mathrm{Kg} / \mathrm{m}^{3}\right)$

$\mu \quad$ Dynamic viscosity, (N.s $\left./ \mathrm{m}^{2}\right)$ $v \quad$ Kinematic viscosity, $=\mu / \rho,\left(\mathrm{m}^{2} / \mathrm{sec}\right)$

$\theta \quad$ Wall angle, (degree)

$\delta \quad$ Boundary layer thickness, (m)

$\delta^{*} \quad$ Boundary layer displacement thickness $=$ $\int_{0}^{\delta}(1-\mathrm{u} / \mathrm{U}) \mathrm{d}, \quad(\mathrm{m})$

$\alpha \quad$ Dimensionless velocity gradient parameter, $=$ $\left(\delta^{*} / \sqrt{\tau_{\mathrm{w}} / \rho}\right) \cdot(\mathrm{du} / \mathrm{dx})$

$\beta$ Dimensionless pressure gradient parameter, = $\left(\delta^{*} / \tau_{\mathrm{w}}\right) \cdot(\mathrm{dP} / \mathrm{dx})$

\section{EXPERIMENTAL SET-UP}

The experimental set-up is composed of a nozzle, straight section, and diffuser. The shape of the diffuser is based on the ratio of $\left(\mathrm{N} / \mathrm{W}_{1}=6.7\right)$ where the length, $\mathrm{N}=200 \mathrm{~cm}$, and the width, $\mathrm{W}_{1}=0.3 \mathrm{~m}$. The core velocity $\mathrm{U}(\mathrm{x})$ through the diffuser is obtained from conservation of mass,

$$
\mathrm{U}(\mathrm{x})=\frac{\mathrm{Uo}}{1+\left(\frac{2 \mathrm{x} \cdot \tan \theta}{\mathrm{W} 1}\right)}
$$

where $\mathrm{x}$ is the distance measured in the downstream direction of the diffuser. The wall angle $(\theta)$ of the diffuser is computed, $2 \theta=4 \mathrm{o}$. The location of separation point was found to occur at $1.58 \mathrm{~m}$ (experimentally), measured from the inlet of the diffuser; The geometry of the flat-walled diffuser is shown in Fig (1).

\section{MEASUREMENTS}

The measurements of velocity and pressure were carried out in a wind tunnel in the Mechanical Engineering Department - Faculty of Engineering, Suez Canal University. The flat-walled diffuser is made of wood except for one side which is made of Plexiglas to facilitate flow observations. The diffuser is divided into six regions, the first region, $\mathrm{x} \cong 0.0-$ $0.3 \mathrm{~m}$, where $\mathrm{x}$ is the distance measured from the inlet of the diffuser; the second region, $\mathrm{x} \cong 0.3-$ $0.55 \mathrm{~m}$, the third regoin , $\mathrm{x} \cong 0.55-0.95 \mathrm{~m}$, the fourth region, $x \cong 0.95-1.75 \mathrm{~m}$, the fifth region, $\mathrm{x}=1.75-1.95 \mathrm{~m}$ and the sixth region, $\mathrm{x}=1.95-2.15 \mathrm{~m}$. The measurements are made using a hot-wire anemometer (the first point near the wall at $0.003 \mathrm{~m}$ ) and 5-hole probe (the diameter of 5-hole probe $=0.003 \mathrm{~m}$, the first point near the wall at $0.015 \mathrm{~m}$ in the separated regions) for measuring velocity and pressure, respectively.

The experimental readings of velocity and pressure were taken at each station [about 20 points, and 0.015 $\mathrm{m}$ between each two successive points. Fig (2) shows the geometry of the flat-walled diffuser and positions of measuring stations. 


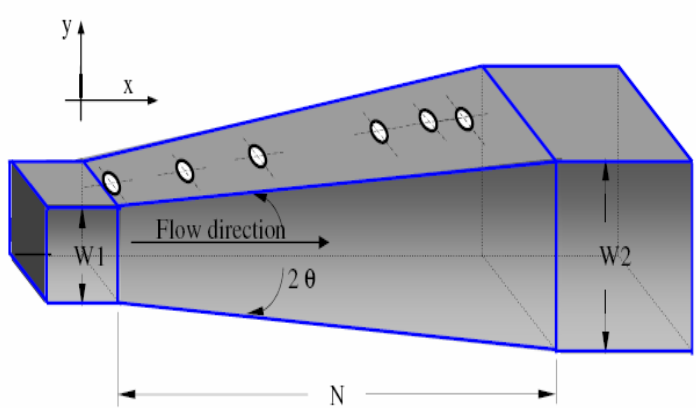

Fig.1 Flat-walled diffuser

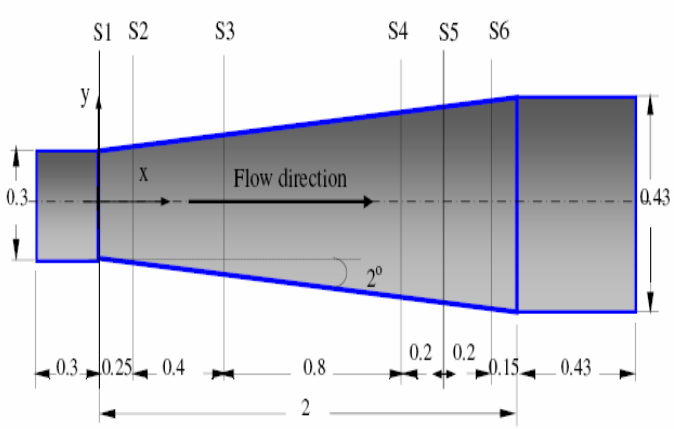

Fig.2 Positions of measuring stations

In Fig.(3), the ambient air is drawn into the heating unit $(9 \mathrm{~kW})$ in the wind tunnel provided that the duct walls are insulated and the heat loss through the duct walls $\left(3.4 \%\right.$ at $\left.\mathrm{Re}=1.68 * 10^{5}\right)$ can be neglected. The mass flow rate is adjusted by the main valve to control the air flow rate, and Reynolds numbers, $(\mathrm{Re}=$ $0.75 * 10^{5}, 1.09 * 10^{5}$, and $1.68 * 10^{5}$ ). However, controlling the temperature of the hot air inside the diffuser $\left(50,46\right.$, and $\left.40{ }^{\circ} \mathrm{C}\right)$ is attributed to changing
Reynolds number and the boundary condition at exit of the diffuser.

the temperature distribution of the hot air through the diffuser at each station, as well as, at the inlet of the diffuser.

The greenhouse effect implementation could be maintained through the downstream boundary condition (cotton screen with impedance, $\mathrm{k}$ and porosity, $\left.\varepsilon_{\mathrm{m}}\right)$. The cotton screen is considered as impedance to slow down the hot air near the exit of However, digital thermometers (measuring range -30 ${ }^{\circ} \mathrm{C}$ to $120{ }^{\circ} \mathrm{C}$, resolution $0.1{ }^{\circ} \mathrm{C}$ ) are used to measure the diffuser. However, the cotton screen creates a pressure drop due to the flow of the hot air through it.

\section{RECOMMENDATIONS FOR CALCULATION OF THE RESISTANCE COEFFICIENT}

The most accurate method of determining the resistance coefficient $(\mathrm{k})$ would be to measure it experimentally for each screen under given flow conditions. For incompressible conditions (Mach number less than 0.05) the resistance coefficient can be determined using the following expression: $\Delta \mathrm{Pe}=$ $\mathrm{k}\left(0.5 \rho \mathrm{U}_{\mathrm{e}}^{2}\right)$, Where $\mathrm{k}=143.92$, and the corresponding value of porosity, $\varepsilon_{\mathrm{m}}=0.06$ can be calculated using the following expression: $\varepsilon_{\mathrm{m}}=1 / \sqrt{1+\frac{\mathrm{k}}{0.52}}$.The suggested expression of porosity can be seen to fit the experimental data better and to underestimate the data only slightly. However, more details can be found in Ref. [15]

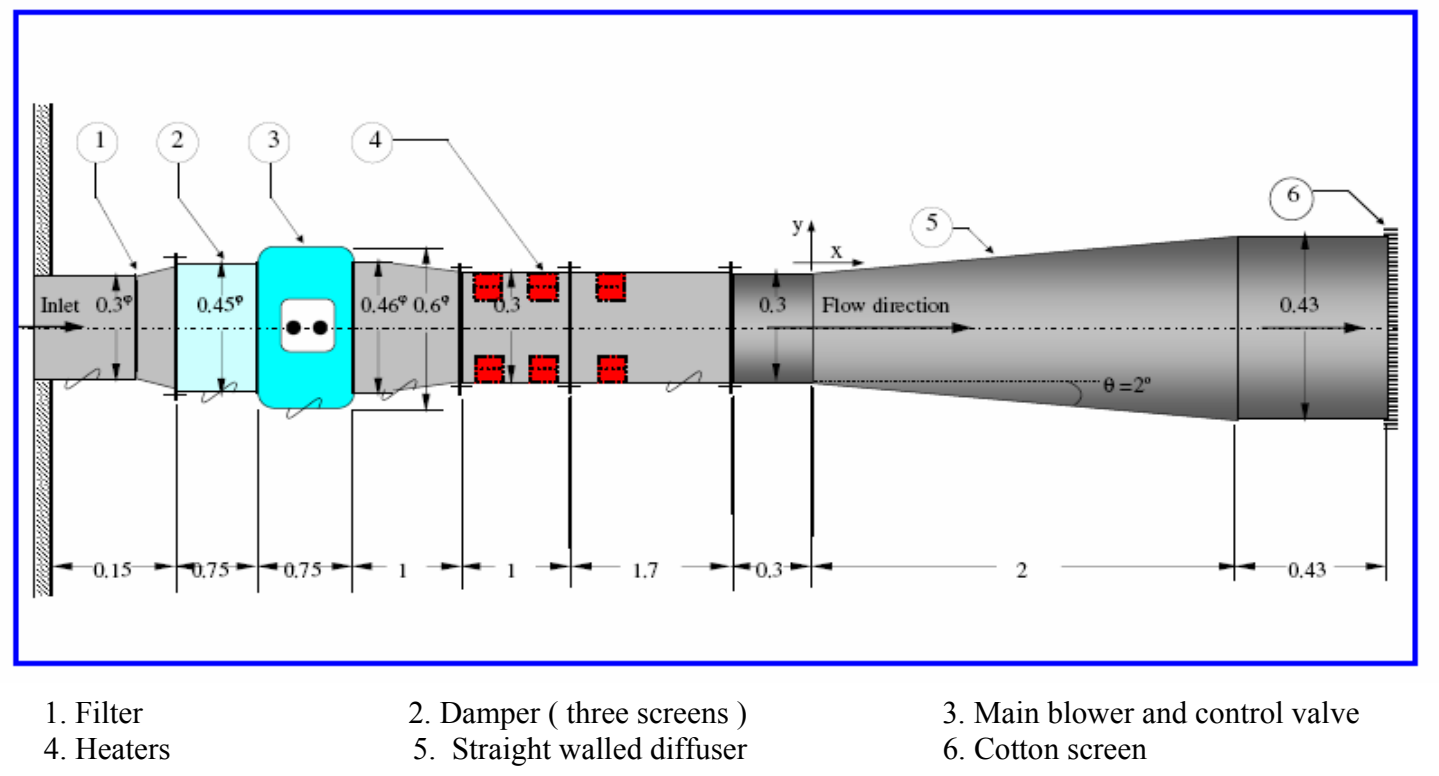

Fig. 3. General layout of the test rig and instruments, dimensions in (m), not to scale 


\section{EXPERIMENTAL UNCERTAINTY}

Velocity measurements are subject to errors in the location of the measurement control volume of the working section particularly, in separated regions. The other parameters recorded during the experimental runs and the respective measurement uncertainties are listed in Table (1). The precision limits seen in the table are the smallest interval between the scale markings (least count) of the perspective instruments. The bias limit for instruments was negligible. An error analysis including the effects of both bias and precision errors, using the root-sum-square method, showed that the uncertainty $[16,17$, and 18] in the measured mean velocity is $\pm 4.6 \%( \pm 0.24 \mathrm{~m} / \mathrm{sec})$ within $95 \%$ confidence. Other uncertainty values are summarized in Table (2).

Table 1 The precision limits for the measured parameters

\begin{tabular}{|l|l|}
\hline \multicolumn{1}{|c|}{ Parameter } & \multicolumn{1}{c|}{ Precision limit } \\
\hline Barometric pressure & $\pm 0.1 \mathrm{~mm} \mathrm{Hg}$ \\
\hline Static pressure gage & $\pm 5 \%$ \\
\hline Dynamic pressure gage & $\pm 5 \%$ \\
\hline Width, $\mathrm{W} 1$ & $\pm 0.1 \mathrm{~mm}$ \\
\hline Length, $\mathrm{N}$ & $\pm 0.1 \mathrm{~mm}$ \\
\hline Diffuser angle, $\theta$ & $\pm 1 \%$ \\
\hline Air density, $\rho$ & $\pm 5 \%$ \\
\hline Inlet velocity, $\mathrm{U}_{\mathrm{o}}$ & $\pm 1 \%$ \\
\hline $\begin{array}{l}\text { Pressure gradient, } \mathrm{dP} / \mathrm{dx} \\
\text { velocity gradient, } \mathrm{du} / \mathrm{dx}\end{array}$ & $\begin{array}{l}\text { twice the standard } \\
\text { deviation of the slope } \\
\text { of }(\mathrm{P}-\mathrm{x}),(\mathrm{u}-\mathrm{x}) \text { plots }\end{array}$ \\
\hline Inlet air temperature & $\pm 0.1{ }^{\circ} \mathrm{C}$ \\
\hline Dynamic viscosity, $\mu$ & $\pm 3 \%$ \\
\hline
\end{tabular}

Table 2 Estimated typical uncertainties

\begin{tabular}{|c|l|}
\hline Parameter & Uncertainty, $\%$ \\
\hline $\mathrm{u}$ & \pm 4.6 \\
\hline $\mathrm{P}$ & \pm 6.83 \\
\hline $\mathrm{Re}$ & \pm 4.74 \\
\hline $\mathrm{Cp}$ & \pm 8.33 \\
\hline $\mathrm{T}$ & $\pm 0 .{ }^{\circ} \mathrm{C}$ \\
\hline$\delta$ & \pm 2.27 \\
\hline$\lambda$ & \pm 4.27 \\
\hline
\end{tabular}

\section{RESULTS AND DISCUSSIONS}

Results of measured velocity, velocity gradient ,pressure gradient , and coefficient of performance are shown in Figs(4) to (8).The analysis of these experimental results indicate that the greenhouse effect can be used to control separation and is likely to be applicable to flat-walled diffusers.
Figure (4) shows the effect of greenhouse adaptation on velocity profiles through the flat-walled diffuser at different Reynolds numbers. As can be seen from Fig. (4.a), the hot air near the exit of the diffuser (station 4, 5 and6) can not resist separation due to the effect of viscosity and thickening the boundary layer. These conditions near the exit of the diffuser have been attributed to the inlet condition of the hot air $(\mathrm{Re}=$ $\left.0.75 * 10^{5}, \quad \mathrm{~T}=50{ }^{\circ} \mathrm{C}\right)$. Therefore, the greenhouse implementation is not effective to prevent or delay separation (the separation point is located at $1.36 \mathrm{~m}$ measured from station 1), and there is a backflow near the exit.

When Reynolds number increases from $\left(0.75 * 10^{5}\right.$ to $1.09 * 10^{5}, \mathrm{~T}=46^{\circ} \mathrm{C}$ ), the viscosity of the trapped hot air near the exit of the diffuser becomes less effective, and the boundary layer thickness decreases. Therefore, the greenhouse implementation becomes more effective in controlling separation. However, the separation point moves forward, and there is a little backflow near the exit of the diffuser (station 6), as shown in Fig. (4.b).

The greenhouse adaptation is clearly indicated to prevent separation for increasing Reynolds number $\left(\operatorname{Re}=1.68 * 10^{5}, \mathrm{~T}=40{ }^{\circ} \mathrm{C}\right)$, as shown in Fig. (4.c). However, this yields a higher momentum for the near-wall fluid particles and, hence, the boundary layer becomes more resistance to separation. Therefore, the velocity profile is fuller and there is no backflow.

It is noticed during the experiments, that the cotton screen is subjected to deformation due to the effect of trapped hot air near the exit of the diffuser. Therefore, it is required to replace the cotton screen for each experiment.

Figure 5 shows the velocity profiles of the flow through the diffuser for different Reynolds numbers $\left(0.75 * 10^{5}, 1.09 * 10^{5}\right.$, and $\left.1.68 * 10^{5}\right)$, at stations 1 , $2,3,4,5$ and 6 , respectively. It is clear that the velocity profiles, Figs $5(\mathrm{a}, \mathrm{b}$ and $\mathrm{c})$ are complete and fuller for all cases of Reynolds numbers.

Figure (5.d) shows the velocity profiles of the flow for different Reynolds numbers, at station (4). As can be seen for $\mathrm{Re}=0.75 * 10^{5}$, the velocity profile is not fuller and has a negative value (backflow), while the other velocity profiles $\left(\mathrm{Re}=1.09 * 10^{5}\right.$ and $1.68 *$ $10^{5}$ ) are fuller. It implies the effect of increasing Reynolds number that the fluid particles near the wall become more resistant to separation.

Figure (5e) shows the velocity profiles for different Reynolds numbers, at station (5). It is clear that the velocity profile is not fuller and backflow occurs, for $\left(\mathrm{Re}=0.75 * 10^{5}\right.$ and $\left.\mathrm{Re}=1.09 * 10^{5}\right)$. It implies that the flow separates, for $\left(\operatorname{Re}=0.75 * 10^{5}\right)$ and the flow is in a critical condition for $\mathrm{Re}=1.09 * 10^{5}$ but, for $\mathrm{Re}$ 


\section{A.S. Abdelhameed A. AbdElmotalip,"Greenhouse Implementation on Flow Separation in Diffusers"}

$=1.68 * 10^{5}$, the flow does not separate as a result of increasing Reynolds number.

Figure (5f) shows the velocity profiles for different Reynolds numbers, at station (6). It can be seen that the flow separates and there are more back flow for $\left(\mathrm{Re}=0.75^{*} 10^{5}\right.$ and $\left.\mathrm{Re}=1.09 * 10^{5}\right)$ but, for $\mathrm{Re}=$ $1.68 * 10^{5}$, the velocity profile is complete and fuller and the flow is capable to resist separation.

Figures 5 (g, h, and k) indicate more details about the velocity profiles near the walls of the diffuser at stations (4, 5 and6), respectively.

In the present investigation, the flow through the diffuser shows some attributes of equilibrium in the initial one third length (stations (1), (2) and (3)). In the second half of the diffuser, (stations (4), (5) and (6)), the velocity profiles indicate a distinct point of inflection, the wall regions have less sensitivity to the initial conditions, and the flow exhibits some insensitivity toward the local boundary conditions. Also, the validity of this result was confirmed for all Reynolds numbers. However, the present work supports the existence of a new non-dimensional pressure and velocity gradient parameters $[\beta=$ $\left(\delta^{*} / \tau_{\mathrm{w}}\right) .(\mathrm{dP} / \mathrm{dx})$ and $\left.\alpha=\left(\delta^{*} / \sqrt{\tau_{\mathrm{w}} / \rho}\right) .(\mathrm{du} / \mathrm{dx})\right]$, respectively. More details about the behavior of the flow in diffuser, in particular, near the exit can be found in Refs [19 to 22].

Figure (6) indicates the development of the pressure gradient parameter, $\beta=\left(\delta^{*} / \tau_{\mathrm{w}}\right) .(\mathrm{dP} / \mathrm{dx})$, through the diffuser at all the stations, and for all cases of Reynolds numbers. It can be seen that the parameter, $\beta$ has a consistent rising trend in the diffuser for $\mathrm{Re}=$ $0.75 * 10^{5}$, (the case of separation and backflow). On the other hand, the parameter, $\beta$, for $\mathrm{Re}=1.09 * 10^{5}$ the increase is less when compared with the case $\mathrm{Re}=0.75 * 10^{5}$, where as the parameter, $\beta$, for $\mathrm{Re}=$ $1.68 * 10^{5}$, increases at the initial stations ( (1), (2) and (3) ) and achieves a nearly constant value in the final stations ( (4), (5) and (6)). Figure (7) shows the development of velocity gradient.

parameter, $\alpha=\left(\delta^{*} / \sqrt{\tau_{\mathrm{w}} / \rho}\right)$. (du/dx) of the flow through the diffuser, for all cases of Reynolds numbers, at the six stations. It is clear that the parameter, $\alpha$ has a consistent decreasing trend in the diffuser for $\operatorname{Re}=0.75 * 10^{5}$. This is the case of separation $\left(0.6<\mathrm{X}^{*}<0.8\right)$, and backflow $\left(0.8<\mathrm{X}^{*}<\right.$ $1.0)$. Also, the velocity gradient parameter, $\alpha$ for $(\mathrm{Re}=$ $1.09 * 10^{5}$ and $\left.1.68 * 10^{5}\right)$ decreases through the diffuser.

Figure (8) shows the relation between the pressure recovery coefficient, $\mathrm{Cp}$ and Reynolds number. It is clear that the value of $\mathrm{Cp}$ is not realistic $(\mathrm{Cp}>1)$, for $\left(\operatorname{Re}=0.75 * 10^{5}\right.$ and $\left.1.09 * 10^{5}\right)$. These values of $\mathrm{Cp}$ are attributed to the greenhouse effect. On the other hand, the greenhouse can be used to control the value of $\mathrm{Cp}$, in particular, for $\mathrm{Re}=1.68 * 10^{5}$. However, $\mathrm{Cp}$ reaches a value of $(\mathrm{Cp}=0.9)$ which is greater than the estimated value $(\mathrm{Cpi}=0.77)$.

\section{CONCLUSIONS}

The present study provides a new method of using greenhouse adaptation to produce desired effects of separation control. However, separation delay, separation prevention, and pressure recovery coefficient improvement can be achieved via the successful using of greenhouse adaptation. This has been validated through the present experimental investigation. The present work supports the existence of new non-dimensional pressure and velocity gradient parameters $\left[\beta=\left(\delta^{*} / \tau_{\mathrm{w}}\right) \cdot(\mathrm{dP} / \mathrm{dx})\right.$ and $\left.\alpha=\left(\delta^{*} / \sqrt{\tau_{\mathrm{w}} / \rho}\right) .(\mathrm{du} / \mathrm{dx})\right]$, respectively. During the experiments, the geometry of the cotton screen ( greenhouse implementation) was subjected to deformation, as a result of the effect of the hot air near the exit of the diffuser. Therefore, the value of the porosity of the cotton screen would be expected to change from one experimental run to another. However, it would be desired to replace the cotton screen every run corresponding to a different value of Reynolds number. The experimental error due to cotton screen deformation is included in an uncertainty analysis.

Measurement techniques applicable to separating flows are limited to methods that able to determine both the magnitude and direction of the flow. This exclude the use of constant temperature hot-wire anemometry (CTA), an otherwise very common and accurate measurement technique for turbulent flows. In separating flows the measurement method used in the present work is 5-hole- probe with error analysis.

\section{REFERENCES}

[1] Lachmann, G.V., "Boundary Layer and Flow Control", Pergamon Press, Oxford, Great Britain, Vol. 1 and 2, 1961.

[2] Colin, P.E., and Williams, J., “Assessment of Lift Augmentation Devices", AGARD-LS-43-71, AGARD, NATO, Rhode-Saint-Genese, Belgium, 1971.

[3] Chang, P.K., "Control of Flow Separation", Hemisphere, Washington, D.C., 1976.

[4] Adkins, R.C., "Diffusers and Their Performance Improvement by Means of Boundary Layer Control", in AGARD Special Course on Concepts for Drag Reduction, AGARD-R-654, Paper No.6, Rhode-Saint-Genese, Belgium, 1977. 
[5] Gad-el-Hak, M., "Flow Control”, Appl. Mech. Rev. 42, pp. 261-293, 1989.

[6] Gad-el-Hak, M., "Control of Low Speed Airfoil Aerodynamics”, AIAA J. 28, pp. 1537-1552, 1990.

[7] Lin, J.C., Howard, F.G., and Selby, G.V., "Control of Turbulent Separated Flow Over a Rearward-Facing Ramp Using Longitudinal Grooves", J. Aircraft 27, pp. 283-285, 1990.

[8] Gad-el-Hak, M., and Bushnell, D.M., "Status and Outlook of Flow Separation Control", AIAA Paper No. 91-0037, New York, 1991a.

[9] Gad-el-Hak, M., and Bushnell, D.M., "Separation Control Review", J. Fluids Eng., 113, pp. 5-30, $1991 \mathrm{~b}$.

[10] Delery, J.M., "Shock Wave/Turbulent Boundary Layer Interaction and its Control", Prog. Aero. Sci. 22, pp. 209-280, 1985.

[11] Viswanath, P.R., "Shock Wave -Turbulent Boundary Layer Interaction and its Control: A Survey of Recent Developments", Sādbanā 12, pp. 45-104, 1988

[12] MacCormack, R.W., "Numerical Solution of the Interaction of a Shock Wave with a Laminar Boundary Layer" $2^{\text {nd }}$ International Conference on Numerical Methods in Fluid Dynamics, 1970.

[13] MacMartion, D.G., Murray, R.M., Verma, A.., and, Paduano, J.D., "Active Control of Integrated Inlet/Compression Systems: Initial Results", Proc. Of ASME Fluid Eng. Division Summer Meeting, New Orleans, Louisiana, May 29-June, 2001.

[14] Driver, D.M., "Experimental Study of a ThreeDimensional Shear-Driven Turbulent Boundary
Layer with Streamwise Adverse Pressure Gradient", Ph. D. thesis, Stanford University, Stanford, CA. 1989.

[15] Noda, H., Yoshioka, K., and Hamatake, T., "An Experimental Study on the Permeability of Screen Wicks", JSME Int. J. Series B, Vol. 36, No. 2, 1993.

[16] Abernethy, R.B., Benediet, R.P., and Dowdell, R.B., "ASME Measurement Uncertainty", ASME Journal of Fluids Engineering, Vol.107, pp.161-164, 1985.

[17]Kline, S.J., "The Purposes of Uncertainty Analysis", ASME Journal of Fluids Engineering, Vol. 107, pp. 153-160, 1985.

[18] Moffat, R.J., "Describing the Uncertainties in Experimental Results", Experimental Thermal and Fluid Science, Vol. 1, No. 1, pp. 3-17, 1988.

[19] Schofield, W. H., "Equilibrium Boundary Layers in Moderate to Strong Adverse Pressure Gradients," Journal of Fluid Mechanics Vol.113, Dec. pp.91- 122, 1981.

[20] Stratford, B., S., “An Experimental Flow with Zero Skin Friction Throughout its Region of Pressure Rise," Journal of Fluid Mechanics, Vol.5, Pt. 1, Jan. pp. 17-35, 1959.

[21] Trupp, A. C., Azad, R.S., and Kassab, S.Z., "Near-Wall Velocity Distributions within a Straight Conical Diffuser," Experiments in Fluids, Vol.4, pp. 319- 331, 1986.

[22] Clauser, F.H.,Turbulent Boundary Layers in Adverse Pressure Gradients," Journal of the Aeronautical Sciences, Vol.21, Feb., pp.91-108, 1954. 

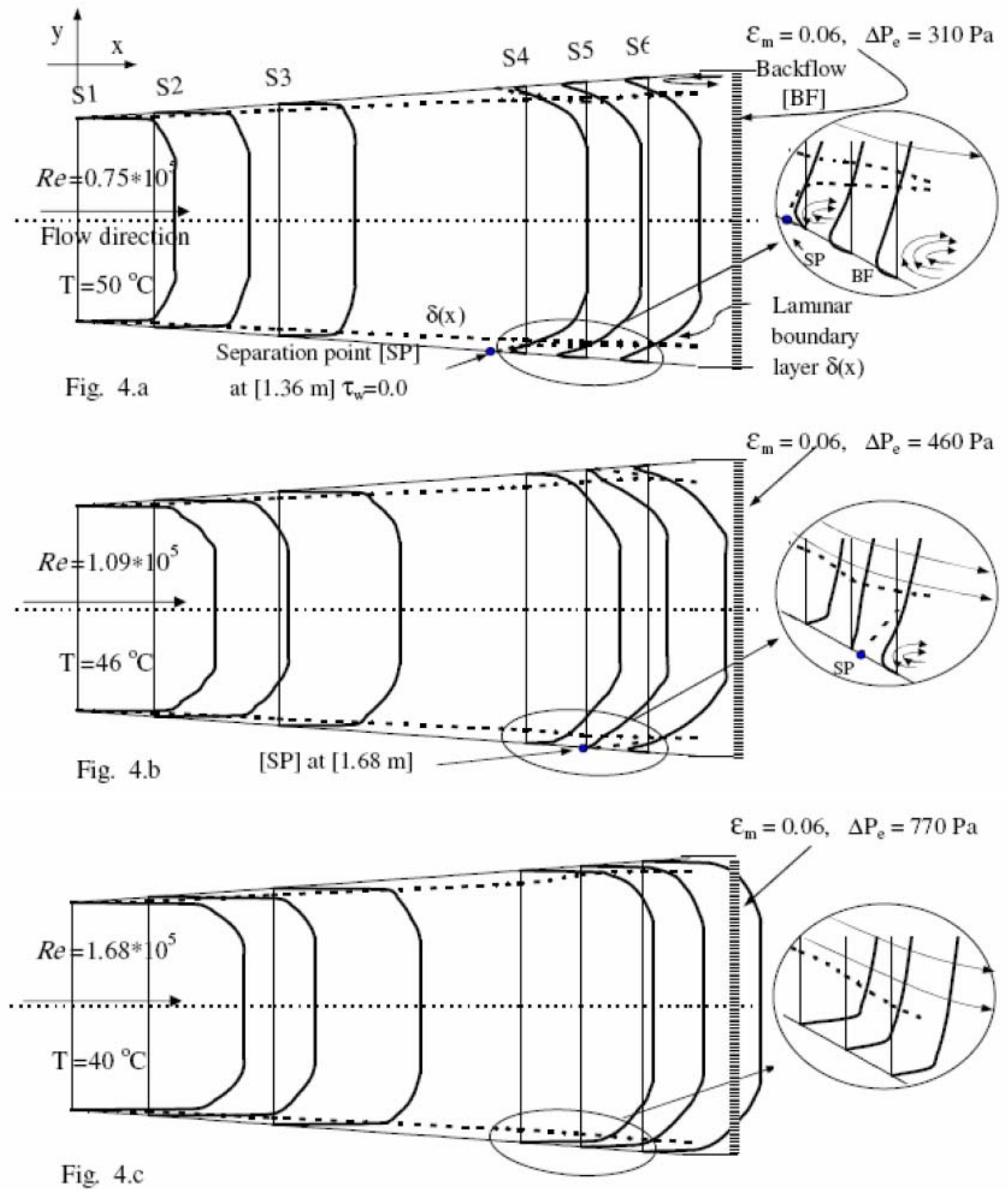

Fig. 4 Velocity distribution of greenhouse effect through the diffuser at different Reynolds number 

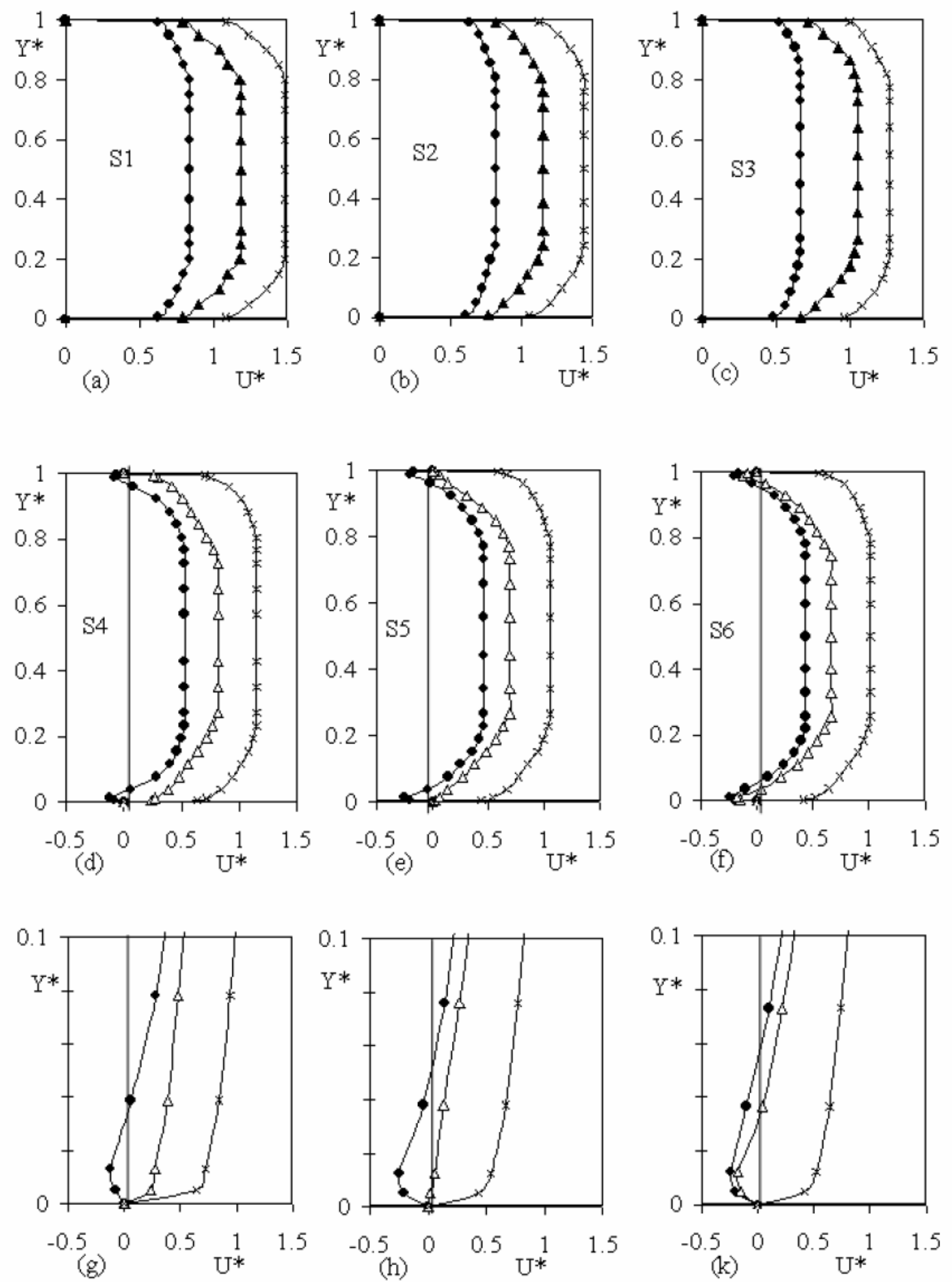

$$
\bullet \operatorname{Re}=0.75 * 10^{5} \quad \triangle \operatorname{Re}=1.09 * 10^{5} \quad \star \operatorname{Re}=1.68 * 10^{5}
$$

Fig. 5 Velocity profiles of hot air 


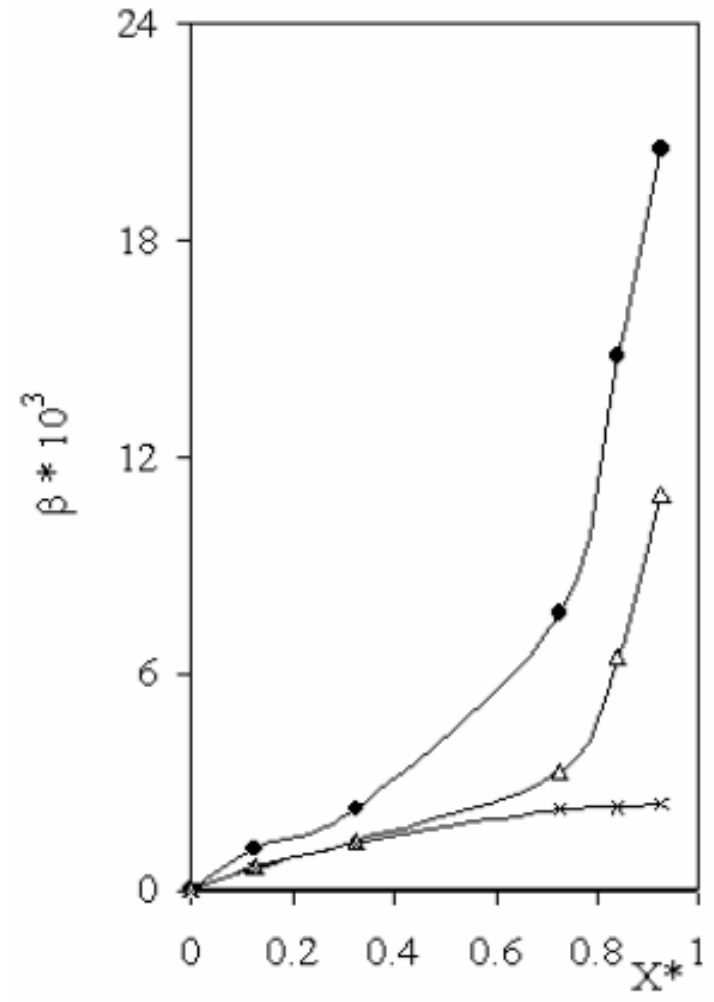

Fig. 6 Development of pressure gradient parameter, $\beta$, in a

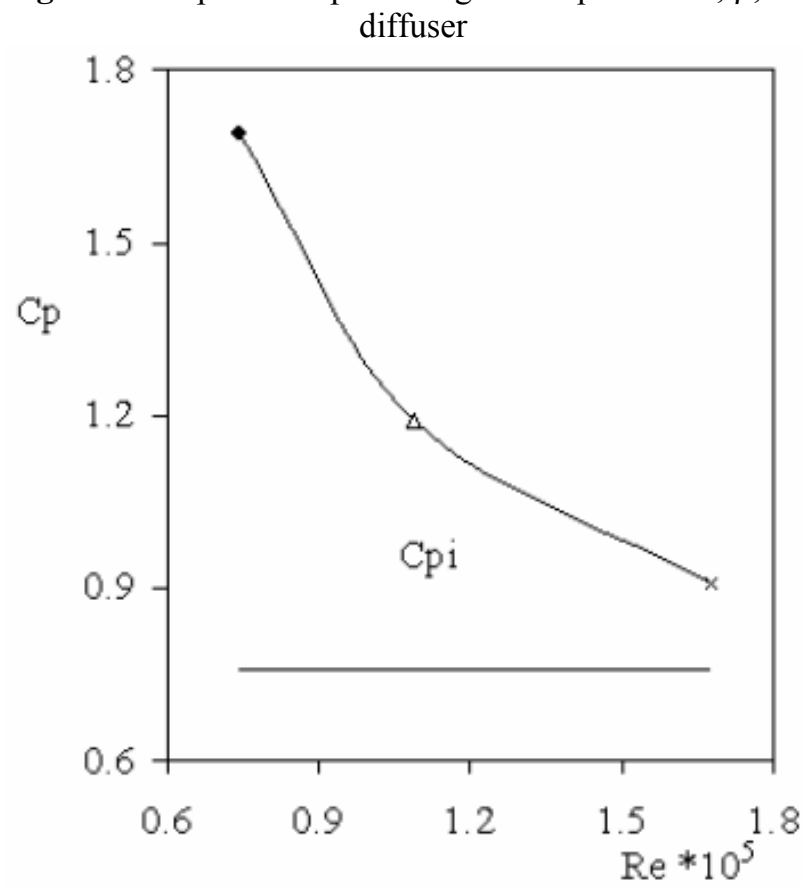

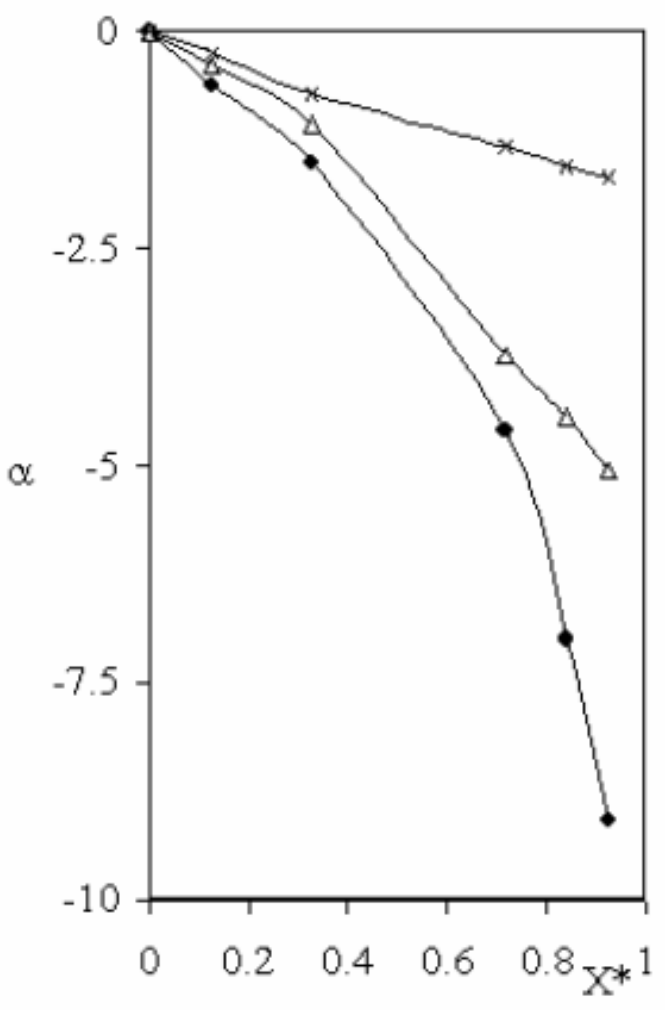

Fig. 7 Development of velocity gradient parameter, $\alpha$, in a diffuser

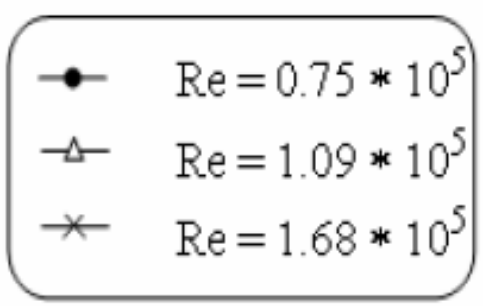

Fig. $8 \mathrm{Cp}$ vs Reynolds number in a diffuser 